\title{
In Vivo Biological Effects of Marine Biosilica on a Tibial Bone Defect in Rats
}

\author{
Matheus de Almeida $\mathrm{Cruz}^{1 *}$ \\ https://orcid.org/0000-0002-9032-9111
}

\section{Paulo Roberto Gabbai-Armelin ${ }^{1}$}

https://orcid.org/0000-0003-4802-0062

Alan de França Santana ${ }^{1}$

https://orcid.org/0000-0001-8213-8262

\section{João Paulo dos Santos Prado ${ }^{1}$}

https://orcid.org/0000-0002-9289-689X

Ingrid Regina Avanzi ${ }^{1}$

https://orcid.org/0000-0001-5948-1484

\author{
Julia Risso Parisi ${ }^{1}$ \\ https://orcid.org/0000-0002-4325-0638
}

\author{
Márcio Reis Custódio² \\ https://orcid.org/0000-0002-7075-0478
}

Renata Neves Granito ${ }^{1}$

https://orcid.org/0000-0002-2094-3845

\section{Ana Claudia Muniz Renno ${ }^{1}$}

https://orcid.org/0000-0003-2358-0514

${ }^{1}$ Federal University of São Paulo (UNIFESP), Department of Biosciences, Santos, SP, Brazil;:2 University of São Paulo (USP), Biosciences Institute, São Paulo, SP, Brazil.

Received: 2019.03.11; Accepted: 2019.11.25.

*Correspondence: allmayda07@gmail.com; Tel.: +551332290223 (M.A.C.)

\section{HIGHLIGHTS}

- BS was isolated from specimens of the marine sponge Tedania ignis collected in the north coast of São Paulo, Brazil.

- BS derived from marine sponges has been used as a promising raw material for bone grafts substitutes and tissue engineering proposes.

- The present work successfully obtained crystalline BS from marine sponges, able of properly interacting with bone tissue.

- The results are very inspiring toward further in vivo investigations.

Abstract: Research on biomaterials of natural origin has gained prominence in the literature. Above all, marine sponges, due to their architecture and structural components, present a promising potential for the engineering of bone tissue. In vitro studies demonstrate that a biosilica of marine sponges has osteogenic potential. However, in vivo works are needed to elucidate the interaction of biosilica (BS) and bone tissue. The objective of the study was to evaluate the morphological and chemical characteristics of BS compared to Bioglass (BG) by scanning electron microscopy (SEM) and X-ray dispersive energy (EDX) spectroscopy. In addition, to evaluate the biological effects of $B S$, through an experimental model of tibial bone defect using histopathological, histomorphometric, immunohistochemical (IHC) and mechanical tests. SEM and EDX demonstrated the successful extraction of BS. Histopathological analysis demonstrated that Control Group (GC) had greater formation of newly formed bone tissue compared to BG and BS, yet BG bone neoformation was greater than BS. However, BS showed material degradation and granulation tissue formation, with 
absence of inflammatory process and formation of fibrotic capsule. The results of histomorphometry corroborate with those of histopathology, where it is worth emphasizing the positive influence of BS in osteoblastic activity. IHQ demonstrated positive VEGF and TGF- $\beta$ immunoexpression for GC, BS and BG. In the mechanical test no significant differences were found. The present results demonstrate the potential of BS in bone repair, further studies are needed other forms of presentation of BS are needed.

Keywords: biosilica; marine biodiversity; biomaterials; biocompatibility; bone repair.

\section{INTRODUCTION}

The worldwide incidence of bone disorders and conditions has trended steeply upward and is expected to double by 2020, especially in populations where aging is coupled with increased obesity and poor physical activity [1]. Although the high prevalence of fractures worldwide, most bone lesions, such as fractures or small size defects, has the ability of healing by itself due to the high regenerative potential of bone tissue $[2,3]$. However, in large traumatic or disease related bone fractures, the process of consolidation could be compromised, resulting in a delay in the process of healing, poor bone repair quality and even in non-union fractures $[3,4]$.

In recent years, bone grafts and biomaterials, especially the synthetic ones, with the potential of stimulating bone tissue metabolism and treating fracture healing have been used with the aim of regenerating damaged parts. However, their use involves some issues especially related to the high costs, side effects with harmful immunological responses and limited availability [5-7]. Biotechnology strategies have been developed trying to overcome these limitations, especially through the development of new therapeutic approaches based on natural biodiversity [8,9]. Natural based bioactive compounds are often more biocompatible and offer a more efficient biological interaction for stimulation of cell growth [10]. In this context, marine life provides a plentiful resource for the development of novel medical orientated products. Among the marine biodiversity, marine sponges (the phylum Porifera) are one of the most promising source of biological elements and molecules with a huge therapeutic potential for a wide range of applications mainly due to its antitumor, antiviral, anti-inflammatory and antibiotic effects [11].

One of the main components of the sponges are marine biosilica (glassy amorphous silica- SiO2), containing water and small amounts of $\mathrm{Al}, \mathrm{Ca}, \mathrm{Cl}, \mathrm{Cu}, \mathrm{Fe}, \mathrm{K}, \mathrm{Na}, \mathrm{S}$, and $\mathrm{Zn}$ [12], which is being considered for biomedical approaches, especially because silica ions are known as an important element to stimulate bone formation [13]. It seems that biosilica displayed beneficial anabolic effects on bone-forming cells (osteoblasts) [14] and adverse effects on bone-resorbing cells (osteoclasts) [15]. Some authors have extracted BS from sponges and demonstrated, through in vitro studies, evidences of BS osteogenic activity and ability to stimulate mineralization, upregulating the expression of genes related to bone cell differentiation and increase cell proliferation $[14,16]$.

Although the positive in vitro evidences of BS toward the stimulation of bone tissue, its effects on the process of bone healing is not known yet. In this context, we hypothesized that BS would stimulate bone growth and bone defect healing, in a more efficient way compared to the well-known Bioglass (BG). Thus, our aim was to investigate the in vivo biological effects of BS using an experimental model of tibial bone defects in rats. Histology, histomorphometry, immunohistochemistry and bone strength were used in the present study.

\section{MATERIAL AND METHODS}

\section{Biosilica extraction}

BS was isolated from specimens of the marine sponge Tedania ignis collected in the north coast of São Paulo, Brazil. The sponges were cut into small pieces and washed with MiliQ water. Firstly, the samples were treated with $5 \%(\mathrm{v} / \mathrm{v})$ sodium hypochlorite to degrade all the organic matter. Then, the material was washed 10 times with MilliQ water to remove the sodium hypochlorite solution. After this, the material was transferred into a beaker containing a solution of nitric acid/sulfuric acid $(1: 4)$ to destroy any remaining organic residue. Finally, several washes were performed using MilliQ water to reach a final $\mathrm{pH}>6.0$ [17]. After all, BS samples were dried in room temperature. Fine powder BS particles were obtained (particle size: $106-126 \mu \mathrm{m}$ ). 


\section{Bioglass (BG)}

Amorphous $\mathrm{BG}$, belonging to the system $\mathrm{SiO}_{2}-\mathrm{CaO}-\mathrm{Na}_{2} \mathrm{O}-\mathrm{P}_{2} \mathrm{O}_{5}$ [18], was produced and provided by Nuclear and Energy Research Institute (particle size: 106 - 126 m; IPEN, São Paulo, Brazil).

\section{Material characterization}

Scanning electron microscopy (SEM) and Energy-Dispersive X-ray spectroscopy (EDX).

BS and BG were first examined by SEM observation (JEOL 6310). The samples were mounted on aluminum stubs using carbon tape and sputter-coated with gold/palladium prior to examination. An EDX coupled to the microscopic scanning system was used to identify the chemical composition of the samples

\section{Surgical procedure}

Thirty healthy young adult male Wistar rats (12 weeks old; weight $295 \pm 29 \mathrm{~g}$ ) were used as experimental animals. The animal experimental plan was reviewed and approved by the Experimental Animal Committee of the 5556130616 and national guidelines for the care and use of laboratory animals were observed.

Animals were distributed in the following groups: control group (GC): animals submitted to the surgical procedure without treatment; Bioglass group (BG): animals submitted to the surgical procedure and treated with bioglass and Biosilica group (BS): animals submitted to the surgical procedure and treated with biosilica.

Anesthesia was induced and maintained by Isoflurane inhalation (Rhodia Organique Fine Limited). To minimize post-operative discomfort, buprenorfine (Temgesic; Reckitt Benckiser Health Care Limited, Schering-Plough, Hoddesdon, UK) was administered intraperitoneally $(0.02 \mathrm{mg} / \mathrm{kg})$ directly after the operation and subcutaneously for 2 days after surgery.

To insert implants into the tibial bone defects, the animals were immobilized on their back and both hind limbs were shaved, washed and disinfected with povidone-iodine. After exposure of the tibial $(10 \mathrm{~mm}$ below the articular line), a $2.0 \mathrm{~mm}$ pilot hole was drilled. The hole was gradually widened with drills of increasing size until a final defect size of $3 \mathrm{~mm}$ in width and $3 \mathrm{~mm}$ in depth was reached. Low rotational drill speeds (max. $450 \mathrm{rpm}$ ) and constant physiologic saline irrigation were used. After preparation, the defects were thoroughly irrigated and packed with sterile cotton gaze to stop bleeding. Surgery was performed in both legs of the rats and one defect was created in each condyle. The pre-set implants were placed in the created defect, according to a randomization scheme ( $n=10$ per experimental group,). Thereafter, the wound was closed with resorbable Vicryl® 5-0 (Johnson\&Johnson, St.Stevens-Woluwe, Belgium) after which the skin was closed by staples (Agraven®; InstruVet BV, Cuijk, The Netherlands) After 2 weeks of implantation, rats were euthanized by OVERDOSE of anesthetic (Ketamine / Xylazine).

\section{Histological procedures}

After harvesting the specimens, the specimens were fixated in $4 \%$ formaldehyde for 2 days, followed by dehydration in a graded series of ethanol and embedding in methylmethacrylate (MMA). After polymerization of the specimens, histological analysis was done. Therefore, for the tibia, thin sections $(5 \mu \mathrm{m})$ were prepared perpendicular to the medial-lateral drilling axis of the implants using a microtome with a diamond blade (Leica Microsystems SP 1600, Nussloch, Germany) [19]. At least, three sections of each specimen were stained with hematoxylin and eosin and submitted to the procedures of histopathological analysis and immunohistochemistry.

\section{Histological and histomorphometrical evaluation}

Histopathological evaluation was performed under a light microscope (Olympus, Optical Co. Ltd, Tokyo, Japan.). Any changes in the bone defect, such as presence of woven bone, medullar tissue, inflammatory process, granulation tissue, or even tissues undergoing hyperplastic, metaplastic and/or dysplastic transformation were investigated per animal. At least three sections of each specimen were examined using light microscopy (Leica Microsystems AG, Wetzlar, Germany) by 2 experienced observers (M.A.C. and J.R.P.).

$\mathrm{N}$ the histomorphometric analysis, a light microscope coupled to a digitizer plate (100X magnification) and the Osteomeasure $\AA$ semiautomatic program (Osteometrics, Atlanta, GA, USA) were used, evaluating BV / TV (\%), OV / TV (\%) and Ob.S / BSf (\%). Measurements were throughout the extension area for the choice of histopathological patterns following standardized nomenclature [20]. 


\section{Immunohistochemistry analysis}

For immunohistochemistry analysis, the streptavidin-biotin-peroxidase method protocol [21,22]. Briefly, resin from the sections was removed with xylene/chloroform (1:1). Then, the specimens were rehydrated in graded ethanol and pre-treated with $0.01 \mathrm{M}$ citric acid buffer $(\mathrm{pH} 6)$ in a steamer for $5 \mathrm{~min}$. To inactivate the endogenous peroxidase was used hydrogen peroxide in phosphate-buffered saline (PBS) for 5 min and blocked with $5 \%$ normal goat serum in PBS for $10 \mathrm{~min}$. Following, the primary antibody was incubated with anti-vascular endothelial growth factor (anti-VEGF, Santa Cruz Biotechnology, USA) at a concentration of 1:200, and anti-transforming growth factor beta (anti-TGF- $\beta$, Santa Cruz Biotechnology, USA) at a concentration of 1:200. The primary antibodies were incubated for $2 \mathrm{~h}$. Then, it was used the biotinconjugated secondary antibody anti-rabbit IgG (Vector Laboratories, Burlingame, CA, USA) at a concentration of 1:200 in PBS for 30 min. Afterwards, samples were incubated with avidin biotin complex conjugated to peroxidase for $30 \mathrm{~min}$. To reveal the immunostaining was used $0.05 \%$ solution of $3-3$ 'diaminobenzidine solution for $5 \mathrm{~min}$ and restained with Harris haematoxylin (Merck) for $4 \mathrm{~min}$. Finally, the specimens were analysed through the qualitatively (presence and location of the immunomarkers) and semiquantitatively assess by using a light microscopy (Leica Microsystems AG, Wetzlar, Germany) according to a previously described scoring scale from 1 to $4: 1=$ absent $(0 \%$ of immunostaining), $2=$ weak $(1-35 \%$ of immunostaining), $3=$ moderate ( $36-67 \%$ of immunostaining), and $4=$ intense $(68-100 \%$ of immunostaining) $[21,23]$. The analysis was performed in a blinded way (M.A.C).

\section{Three bending test}

Biomechanical analysis was performed using the three-point flexion test, which was performed in the right tibia of the animals of all groups. The biomechanical tests were performed on the Instron universal model machine, model 4444, at room temperature. For the test, a load cell with a maximum capacity of $1 \mathrm{KN}$ and a pre-load of $5 \mathrm{~N}$. A metal bracket $3.8 \mathrm{~cm}$ long was used, exposing only $1.8 \mathrm{~cm}$ of the specimen. The tibias were positioned with the region of the defect facing down, in order to submit this region to a traction according to the model used in the work of Lirani-Galvão and coauthors [24]. From this test, the following variables were obtained: maximum load $(\mathrm{KN})$, resilience $(\mathrm{J})$ and toughness $(\mathrm{J})$.

\section{Statistical analysis}

Data were expressed as mean \pm standard deviation. Statistical analyses were performed using GraphPad Prism 6 (GraphPad Software, San Diego, CA, USA). Shapiro-Wilk normality test was used to check distribution. Mann-Whitney or Kruskal-Wallis test and Dunn post hoc were used for nonparametric data. $T$ test and One-way analysis of variance (ANOVA) with Tukey multiple comparisons post-tests were used for parametric data. Differences were considered significant at $p \leq 0.05$.

\section{RESULTS}

\section{SEM/EDX}

Figure 1 illustrates SEM photomicrographs of all experimental groups (at 300, 500 and $5000 \mathrm{X}$ ). It can be observed that $B G$ particles present an irregular structure and sizes, in the form of granules (Figures $1 \mathrm{~A}$, $1 \mathrm{~B}$ and $1 \mathrm{C})$. BS was seen in the shape of spicules, also with different forms (Figures 1D, 1E and 1F). 

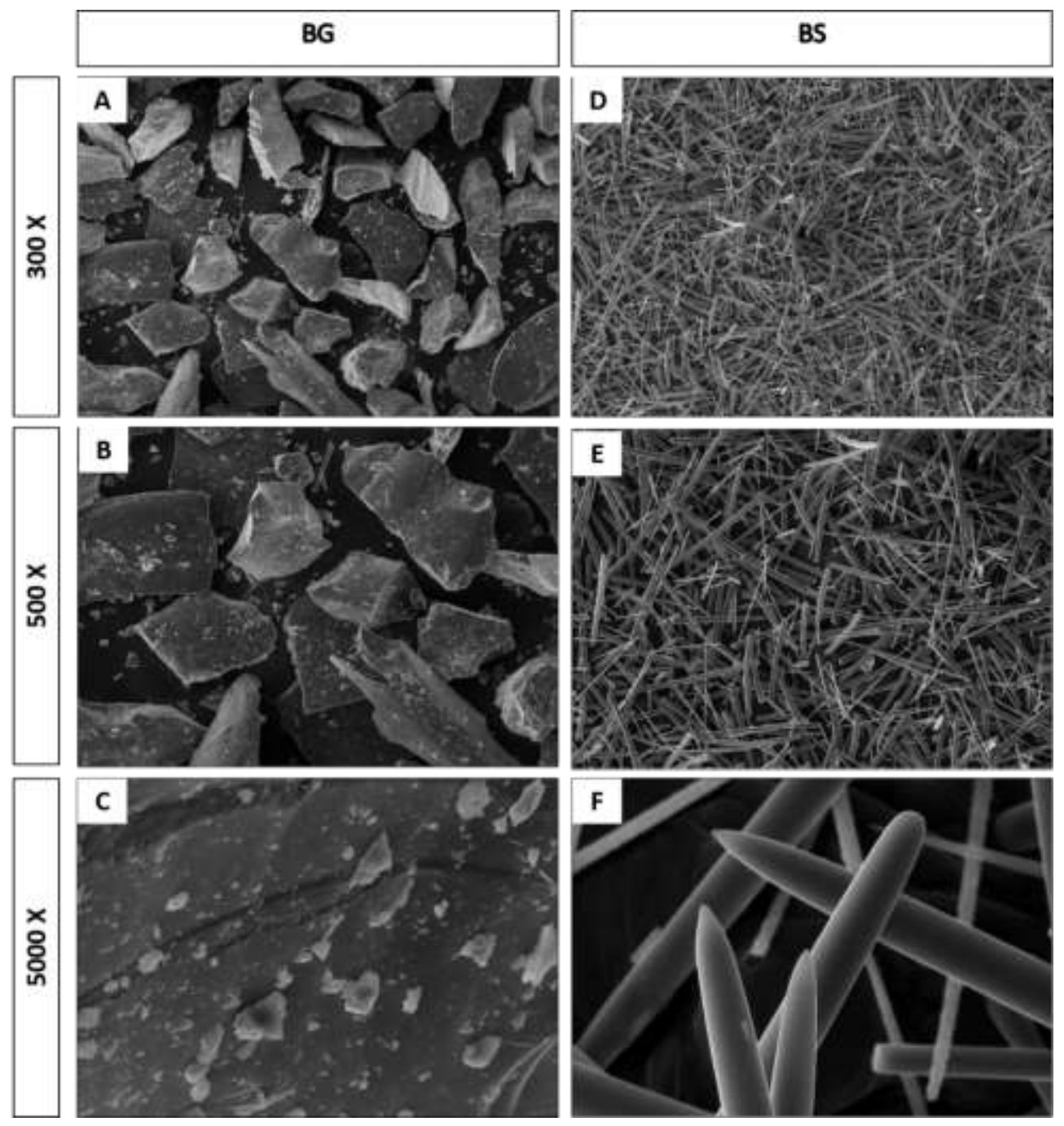

Figure 1. Photomicrographs of SEM of BG (1.A, 1.B and 1.C) and BS (1.D, 1.E and 1.F) where BS spike-shaped structures and amorphous $B G$ particles can be observed respectively.

EDX analysis of BS showed the presence of Si (50.33\%) and O (49.67\%) elements. In addition, for BG, the analysis indicated the presence of $\mathrm{O}$ (43.88\%), $\mathrm{Na}(13.51 \%), \mathrm{Mg}(0.03 \%), \mathrm{Al}(3.93 \%), \mathrm{Si}$ and $\mathrm{P}(2.91 \%)$ (Figure 2).
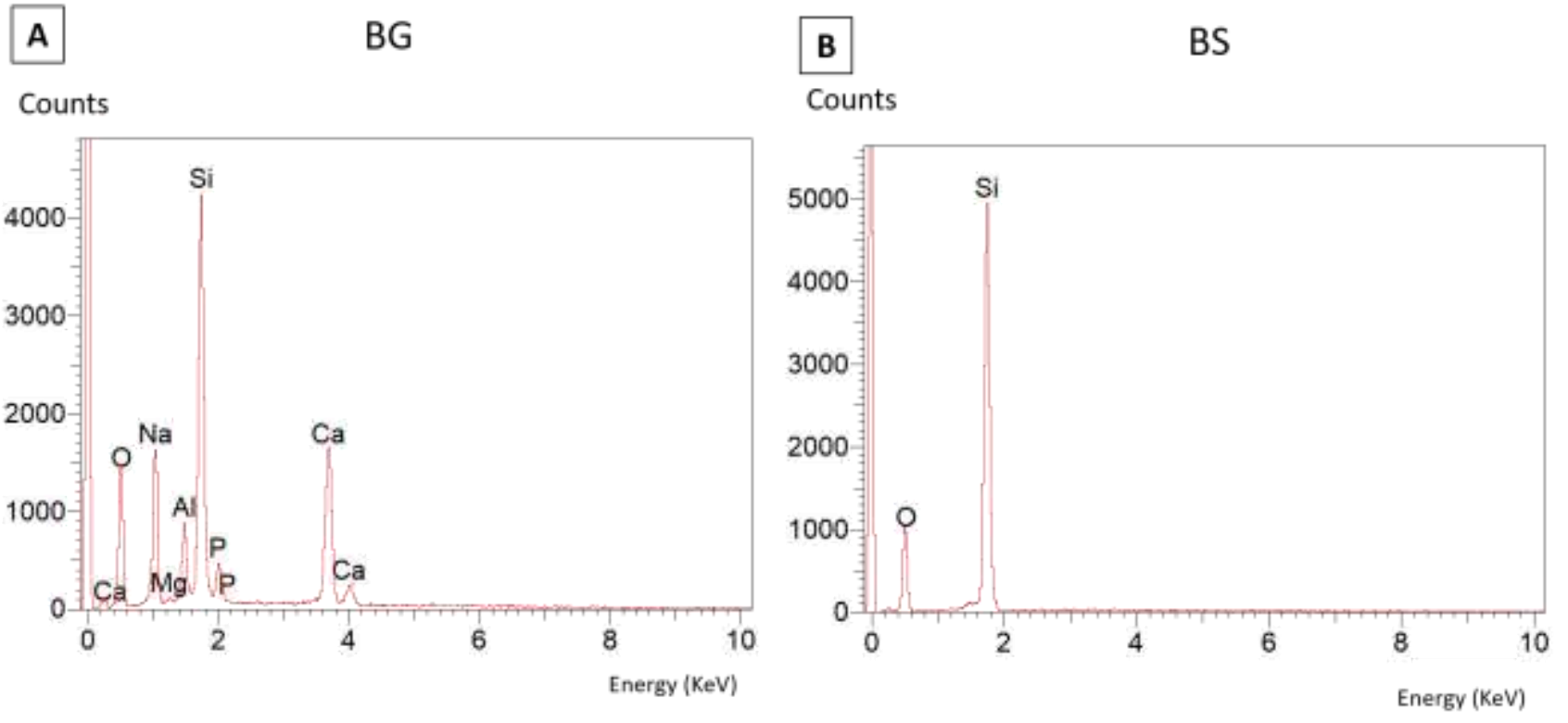

Figure 2. $E D X$ spectra of $B G(A)$ and $B S(B)$, demonstrating the presence of elements contained in each sample. 


\section{Histopathological analysis}

Figure 3 presents the histological findings of all experimental groups, 15 days post-surgery. For CG, bone defect area was filled mostly with granulation tissue surrounded by newly formed bone tissue (Figures 3A and $3 \mathrm{~B}$ ). For BS, granulation tissue filled most of defect with some areas of newly formed bone, mainly in the peripheral area. Also, some particles of the material still could be observed (Figures 3C and 3D). An intense amount of material particles still could be seen in BG treated animals. Granulation tissue surrounding the material particles was observed with some areas of neoformed bone tissue (Figure 3E and 3F). No inflammatory process or fibrous capsule formation was observed around their particles.
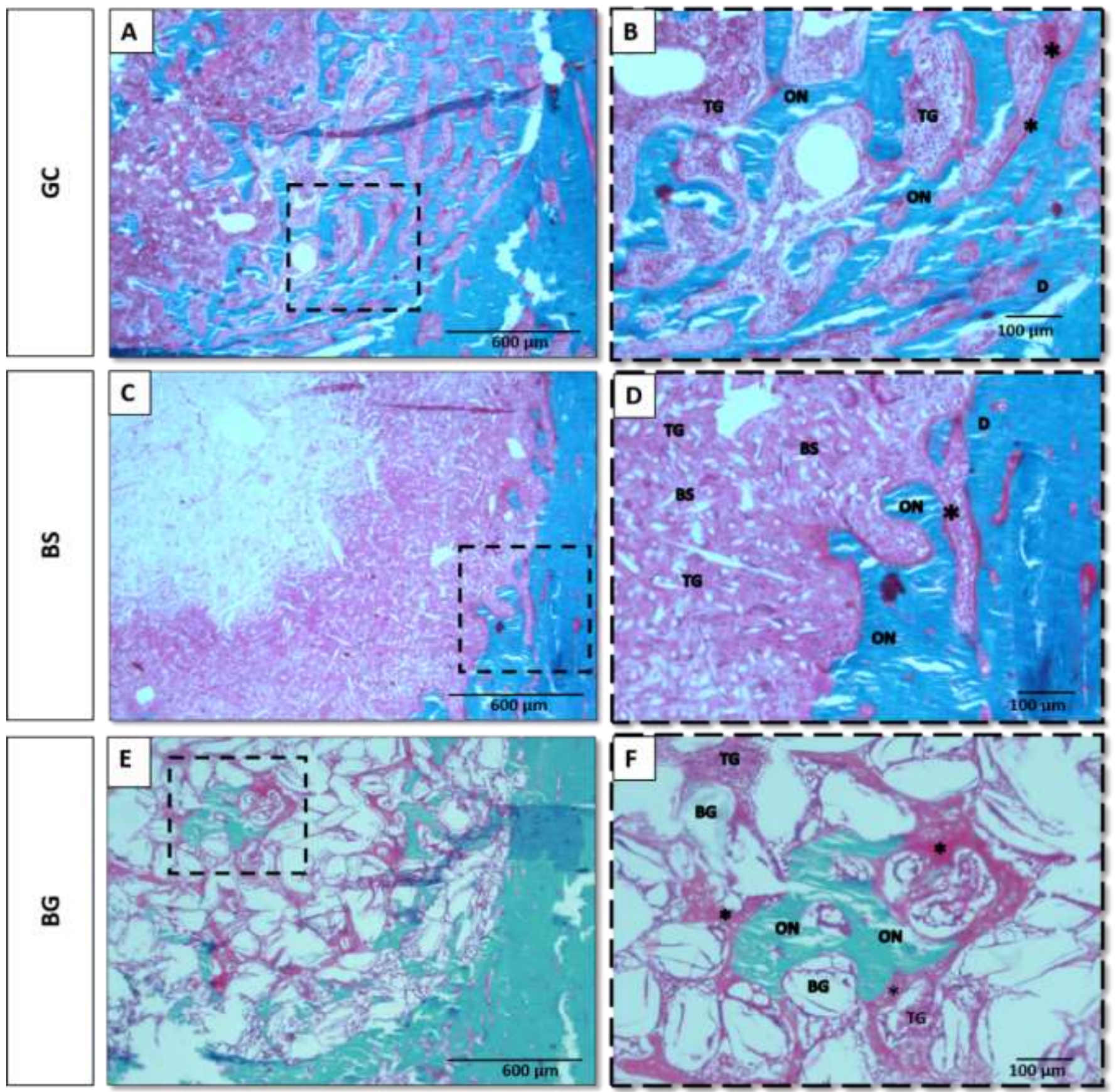

Figure 3. Photomicrographs of SEM of BG (1.A, 1.B and 1.C) and BS (1.D, 1.E and 1.F) where BS spike-shaped structures and amorphous $B G$ particles can be observed respectively.

\section{Histomorphometric analysis}

For Bv/Tv\%, significant higher values were found for GC compared to BS $(p=0.0002)$ and BG $(p=$ 0.0001 ). Moreover, $B G$ treated animals showed higher values for $B v / T v \%$ variable when compared to $B S$ ( $p=$ 0.0003) (Figure 4A). 
On the other hand, BG showed higher values of Ov / Tv (\%) when compared to BS $(p=0.0024)$. Finally, for Ob.S/BSf, similar findings were observed between the groups, as can be observed in Figure 4C.
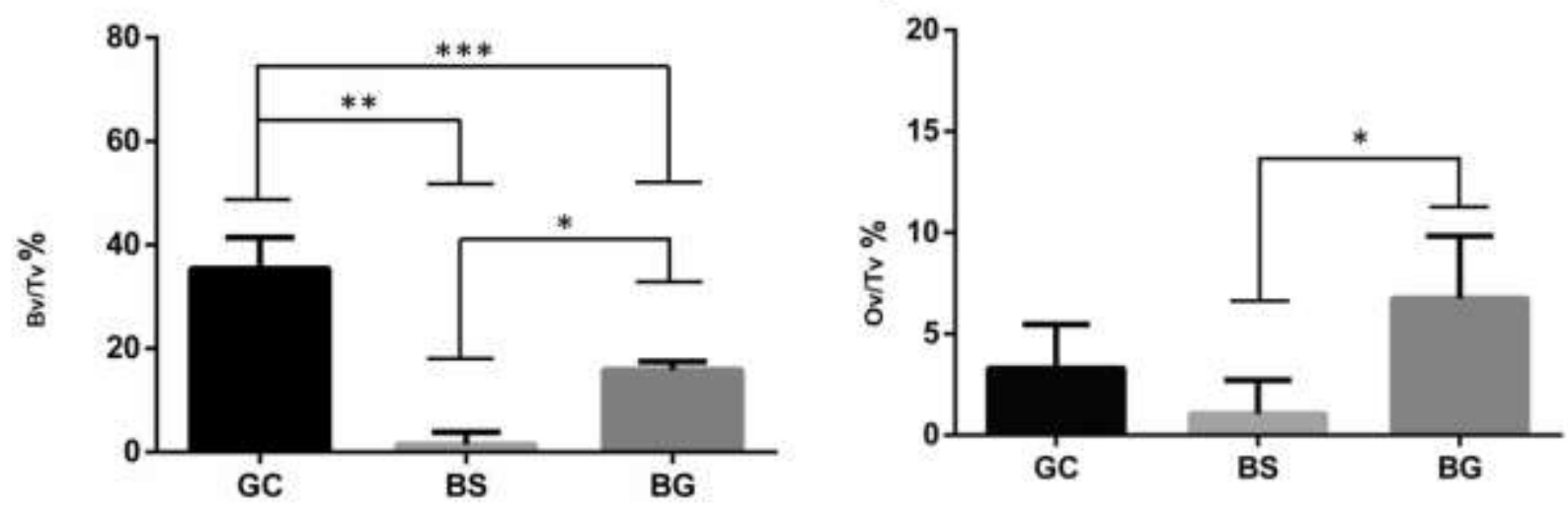

Figure 4. Graphs related to the analysis of histomorphometry parameters: Bv / Tv (\%) showing statistical differences between all BG groups vs. BS $\left({ }^{*}\right)$, BS vs. GC $\left({ }^{* *}\right)$ and BG vs. GC $\left(^{* * *}\right)$. Ov / Tv plot (\%) in which significant statistical difference can be observed between BS vs. BG $\left(^{*}\right)$.

\section{Immunohistochemistry}

GC animals presented TGF- $\beta$ immunolabelling mainly in granulation tissue (Figures $5 \mathrm{~A}$ and $5 \mathrm{~B}$ ). For BS, immunolabelling was observed in the granulation tissue along the entire region of the defect (Figure $5 \mathrm{C}$ and 5D). BG, immunolabelling was observed mainly in newly formed bone (Figure 5E and 5F). 


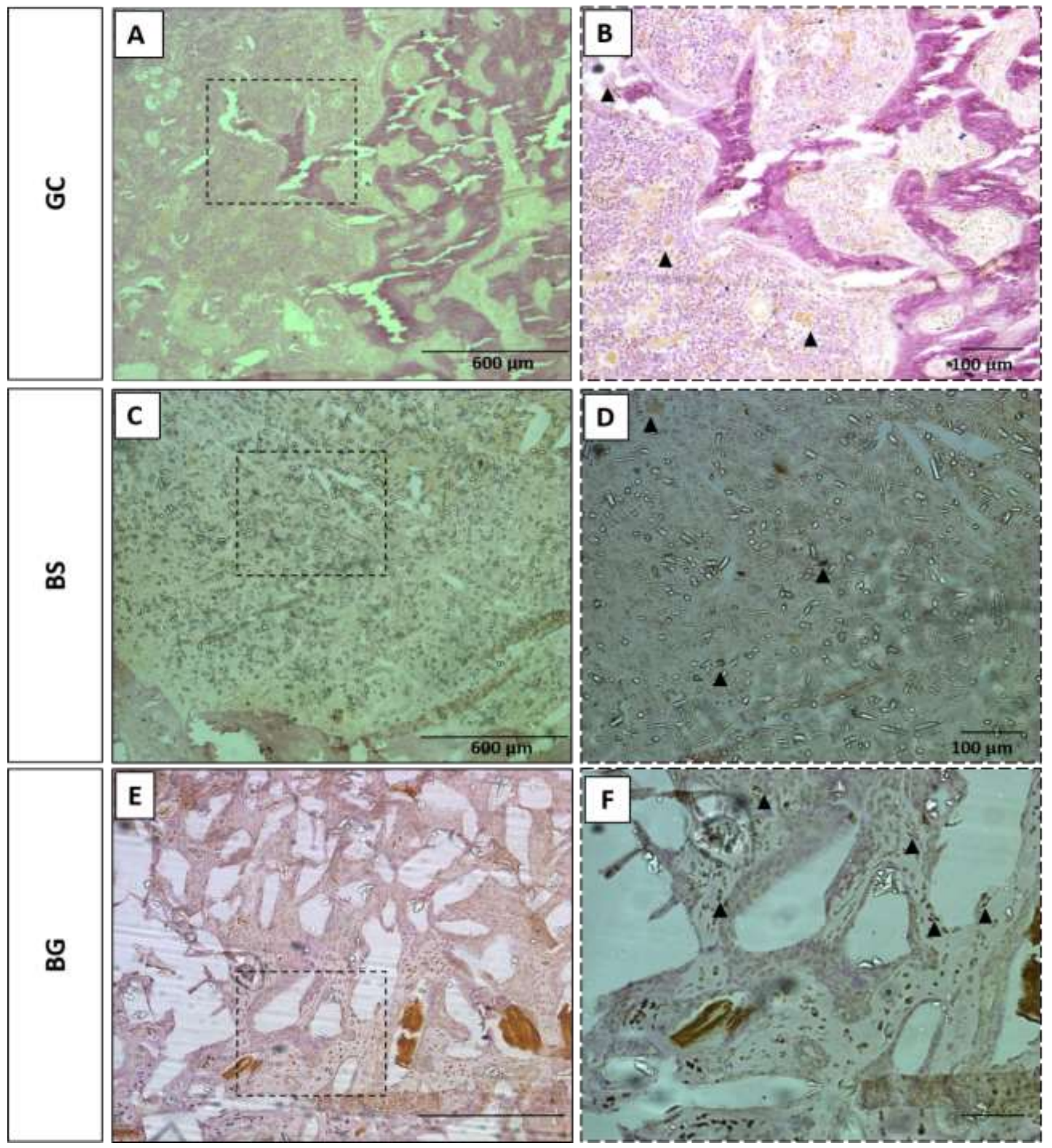

Figure 5. Ihq photomicrograph for the TFG- $\beta$ marker of GC, BS and BG slides for the period of 15 days. A, C, and E are images made at 100X magnification and images $\mathrm{B}, \mathrm{D}$, and $\mathrm{F}$ made at 200X magnification. Immunolabeling pointed by black arrows.

VEGF analysis demonstrated that, for GC, an immunolabelling was observed in granulation tissue along the entire defect (Figures $6 \mathrm{~A}$ and $6 \mathrm{~B}$ ). For BS and BG, immunolabelling of this immunomarker was seen throughout the granulation tissue and material particles (Figures $6 \mathrm{C}$ and $6 \mathrm{D}-\mathrm{F}$ ). In the semi-quantitative analysis similar findings were observed for all groups $(p>0.05)$. 

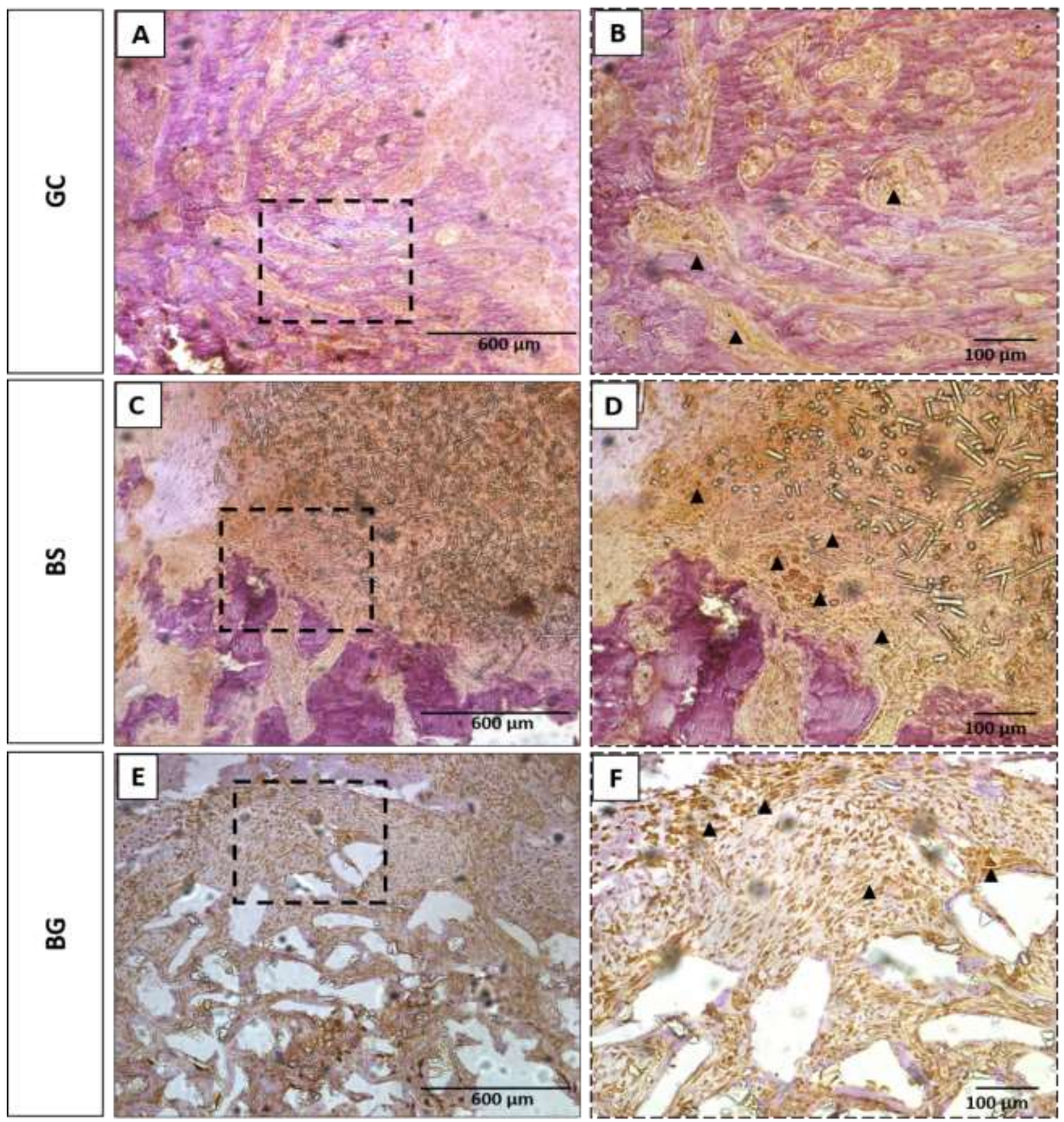

Figure 6. Ihq photomicrograph for the VEGF marker of GC, BS and BG slides for the period of 15 days. A, C, and E are images made at 100X magnification and images $\mathrm{B}, \mathrm{D}$, and $\mathrm{F}$ made at $200 \mathrm{X}$ magnification. Immunolabeling pointed by black arrows.

The semi-quantitative analysis demonstrated the lack of significant statistical differences $(p>0.05)$ (Figure 7). 
A

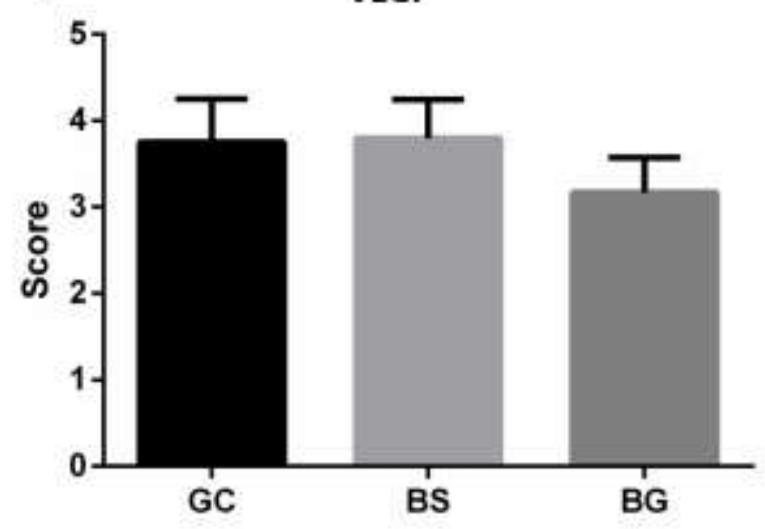

B

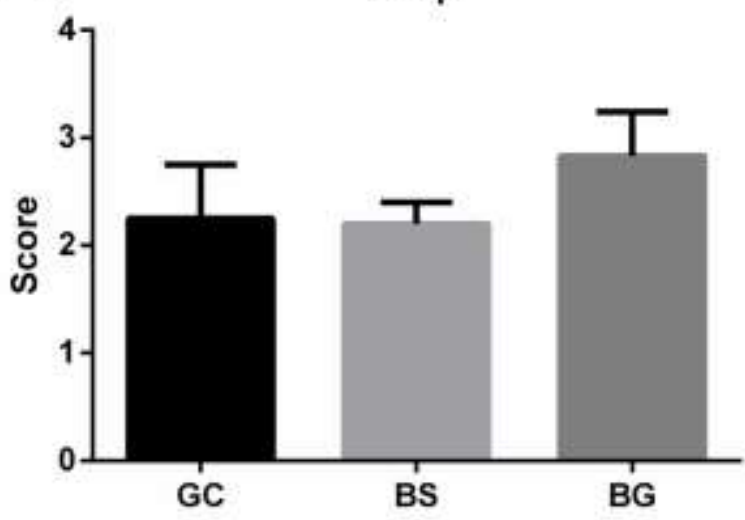

Figure 7. Graphcs of IHQ Ihq graphs for the VEGF (A) and TGF- $\beta$ (B) markers demonstrating the absence of statistical differences.

\section{Three Bending Test}

For the three bending test, no statistical difference was observed among groups for any evaluated variable (maximum load, tenacity and resilience) (Figure 8 ).
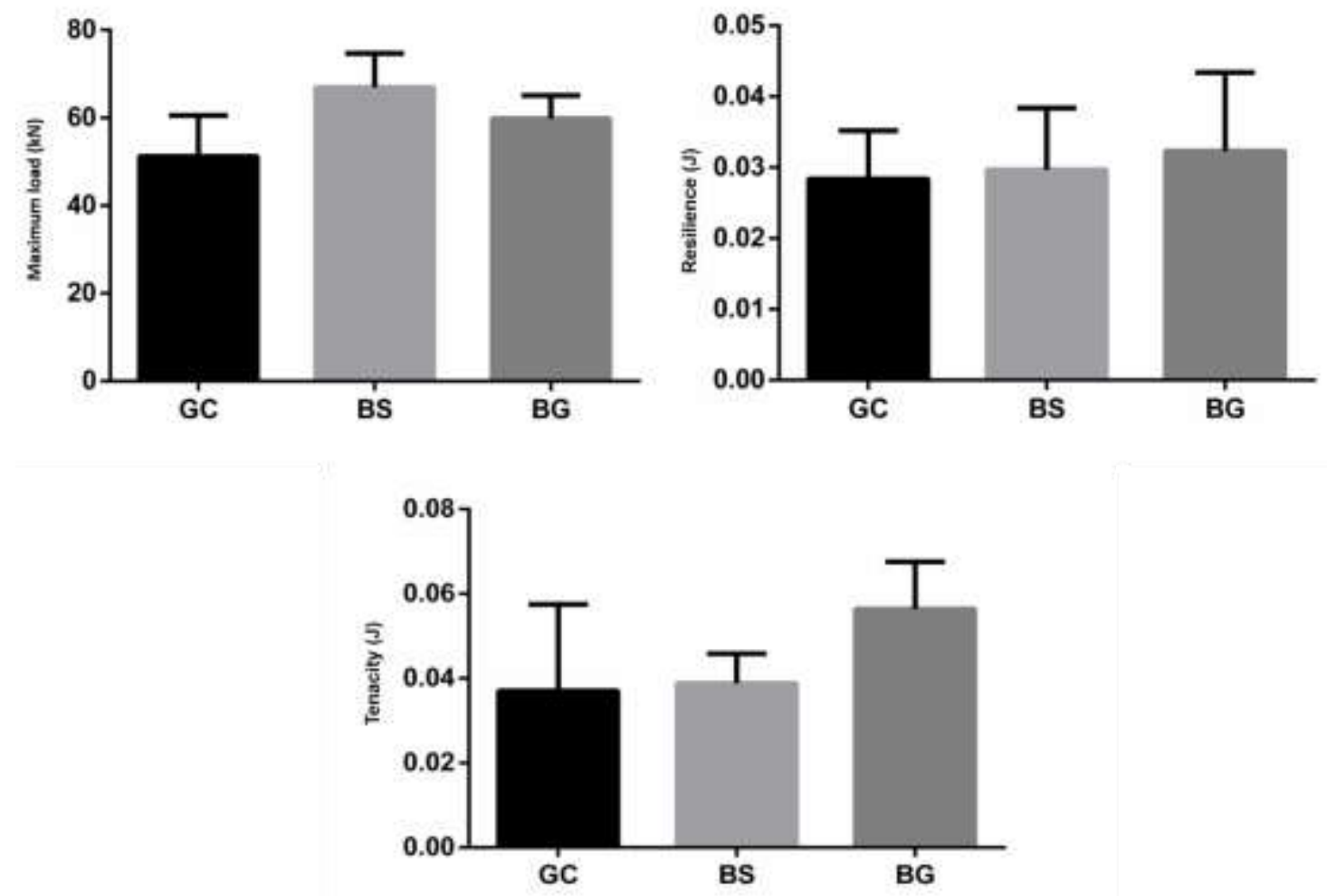

Figure 8. Graphs of biomechanical test variables: Maximum load $(\mathrm{N})$, Resilience $(\mathrm{J})$ and Tenacity $(\mathrm{J})$. No statistical differences were found ( $p>0.05)$.

\section{DISCUSSION}

This study aimed to evaluate the effects on in vivo tissue response of marine BS into a tibial bone defect in rats after 15 days of implantation. It was hypothesized that BS would constitute a material with improved osteogenic properties for bone growth. SEM images demonstrated the presence of irregular BS spicules, showing that the protocol of extraction was successful. Also, the main findings of the tibial bone implantation demonstrated an intense degradation of the material, with granulation tissue filling most of the defect (with some areas of newly formed bone). Histomophometry analysis showed higher values of Bv/Tv\% and Ov/Tv\% 
for BG compared to the BS. Immunohistochemistry analysis and mechanical test demonstrated that similar finding were observed for all groups.

BS derived from marine sponges has been used as a promising raw material for bone grafts substitutes and tissue engineering proposes. BS treated tibial bone defect presented an accelerated material degradation, with an intense ingrowth of granulation tissue into the defect area [25-28]. It is well known that silica ion is an important element for bone formation stimulation [17,29] and interaction with bone tissue, allowing the formation of a silica gel layer. This layer constitutes a template for calcium and phosphate deposition, which attracts macrophages, mesenchimal stem cells and osteoprogenitor cells [30,31]. In this context, BS has showed to display beneficial effects on bone-forming cells (osteoblasts) and adverse effects on bone-resorbing cells (osteoclasts) [27,32]. An in vitro study of our group demonstrated that marine BS presents non-cytotoxicity and had a positive influence on osteoblast cell viability [28]. Furthermore, gene analysis showed that this material up-regulated Runx2 and BMP4 gene expression. In this context, these encouraging in vitro data on the use of BS for tissue engineering proposes formed the basis for the current in vivo study. Although, the histomorphometry demonstrated higher values of the analyzed parameters for $B G$, the intense BS degradation may constitute a very positive characteristic of the material [33,34]. It is well known that, for bone replacement, resorption of bone substitute is required, since ingrowth of newly tissue into the defect area needs the liberation of space $[33,34]$. The results of the current study indicate that the degradation rate of the material indeed substantially influences the formation of granulation tissue in this intermediate period of bone repair. It may be suggested that, higher amounts of newly formed bone would be observed in a late period of bone healing for BS treated animals.

The immunohistochemistry analysis demonstrated that all groups presented similar immulabelling of TGF $\beta, 15$ days post-surgery. TGF $\beta$ plays a very important role in stimulating matrix protein synthesis and bone cell proliferation and, consequently bone remodeling $[35,36]$. However, both BS and BG had no effects on the staining of this immunomarker which possibly may be related to the experimental period evaluated in this study.

Moreover, VEGF is the main mediator during the process of angiogenesis and newly blood vessels formation [37]. In the present study, a similar labelling for this immunomarker was observed for all experimental animals. It has been reported that BG has a stimulatory effect on neovascularisation by stimulating the secretion of angiogenic factors [38,39], which together with the osteopromotive ability of BG influence bone formation. These statements did not corroborate with the findings of the present study. It can be hypothesized that the difference may be related to the experimental periods post-surgery.

Mechanical evaluation of the tibiae showed no statistical difference for maximal load, resilience and tenacity when comparing the experimental groups. Callus strenght is dependented of a series of factors including both the amount and the quality of bone [40]. Additionally, the geometry and the arrangement of its microstructural elements also influences bone mechanical properties [41]. The lack of results in the biomechanical properties found in this study may be explained by the experimental period post-surgery analyzed, which may not be enough to induce sufficient increase in bone mass deposition in the site of the injury that could lead to an increase of bone strength. These results are in agreement with Granito and coauthors [42] and Wheeler and coauthors [43], who also found no significant differences in the biomechanical properties of bone callus treated with BG in experimental models of bone defects.

It is worthwhile to notice that the present study was limited to relatively short-term evaluation of the performance of present biomaterials used and detailed information on the long-term performance of BS remains to be provided. Following this line, further investigations are necessary in order to validate the effect of BS as safe and efficient material for biomedical applications.

\section{CONCLUSION}

The present work successfully obtained crystalline BS from marine sponges, able of properly interacting with bone tissue, presenting a good degradation rate and allowing granulation tissue ingrowth. Our results are very inspiring toward further in vivo investigations are necessary to validate its biological performance for an optimized bone repair. Additionally, different forms of BS presentation (i.e., composites or scaffolds) and longer experimental periods must be performed to clarify the osteogenic potential and biological performance of this biomaterial.

Acknowledgments: The authors thank the Center of Marine Biology (CEBIMar) of the University of São Paulo (USP) for the collaboration on the project no. 938. RNG would like to thank to the Conselho Nacional de Desenvolvimento Científico e Tecnológico (CNPq) for their grant and scholarship (Sciences Without Borders - Young Talents Attraction 
Program). PRGA would like to acknowledge Fundação de Amparo à Pesquisa do Estado de São Paulo (FAPESP) for the grant n. 2015/20704-8

Conflicts of Interest: The authors declare no conflict of interest.

\section{REFERENCES}

1. Amini AR, Laurencin CT, Nukavarapu SP. Bone Tissue Engineering: Recent Advances and Challenges. Crit Rev Biomed Eng. 2012;40(5):363-408.

2. Meyer U, Joos U, Wiesmann HP. Biological and biophysical principles in extracorporal bone tissue engineering. Part III. Int J Oral Maxillofac Surg. 2004;33(7):635-41.

3. O'Keefe RJ, Mao J. Bone Tissue Engineering and Regeneration: From Discovery to the Clinic-An Overview. Tissue Eng Part B Rev. 2011;17(6):389-92.

4. Szpalski C, Barr J, Wetterau M, Saadeh PB, Warren SM. Cranial bone defects: current and future strategies. Neurosurg Focus. 2010;29(6):E8.

5. Humphrey EL, Williams JHH, Davie MWJ, Marshall MJ. Effects of dissociated glucocorticoids on OPG and RANKL in osteoblastic cells. Bone. 2006;38(5):652-61.

6. William Axelrad T, Kakar S, Einhorn TA. New technologies for the enhancement of skeletal repair. Injury. 2007;40(10):195-8.

7. Drosse I, Volkmer E, Capanna R, Biase P De, Mutschler W, Schieker M. Tissue engineering for bone defect healing: An update on a multi-component approach. Injury. 2008;39(SUPPL.2):S9-20.

8. Choi JH, Kim DK, Song JE, Oliveira JM, Reis RL, Khang G. Silk Fibroin-Based Scaffold for Bone Tissue Engineering. Adv Exp Med Biol. 2018;1077(10):371-87.

9. De Oliveira E Silva M, Pelegrine AA, Alves Pinheiro Da Silva A, Manhães Júnior LR, De Mello E Oliveira R, Gaiba França $S$, et al. Xenograft enriched with autologous bone marrow in inlay reconstructions: $A$ tomographic and histomorphometric study in rabbit calvaria. Int J Biomater. 2012;1155(10):1-7.

10.Lin Z, Solomon KL, Zhang X, Pavlos NJ, Abel T, Willers C, et al. In vitro evaluation of natural marine sponge collagen as a scaffold for bone tissue engineering. Int J Biol Sci. 2011;7(7):968-77.

11.Capuzzo E, Stephens D, Silva T, Barry J, Forster RM. Decrease in water clarity of the southern and central North Sea during the 20th century. Glob Chang Biol. 2015;21(6):2206-14.

12. Ehrlich H, Bazhenov V V., Debitus C, de Voogd N, Galli R, Tsurkan M V., et al. Isolation and identification of chitin from heavy mineralized skeleton of Suberea clavata (Verongida: Demospongiae: Porifera) marine demosponge. Int J Biol Macromol. 2017;104(16):1706-12.

13.Wang S, Wang X, Draenert FG, Albert O, Schröder HC, Mailänder V, et al. Bioactive and biodegradable silica biomaterial for bone regeneration. Bone. 2014;67:292-304.

14. Wiens M, Wang X, Schlomacher U, Lieberwirth I, Glasser G, Ushijima H, et al. Osteogenic potential of biosilica on human osteoblast-like (SaOS-2) cells. Calcif Tissue Int. 2010;87(6):513-24.

15.Müller WEG, Wang X, Cui FZ, Jochum KP, Tremel W, Bill J, et al. Sponge spicules as blueprints for the biofabrication of inorganic-organic composites and biomaterials. Appl Microbiol Biotechnol. 2009;83(3):397-413.

16.Granito RN, Custodio MR, Renno ACM. Natural marine sponges for bone tissue engineering: The state of art and future perspectives. J Biomed Mater Res B Appl Biomater. 2017;105(6):1717-27.

17. Weaver JC, Pietrasanta LI, Hedin N, Chmelka BF, Hansma PK, Morse DE. Nanostructural features of demosponge biosilica. J Struct Biol. 2003;

18. Hench LL, Jones JR. Bioactive Glasses: Frontiers and Challenges. Front Bioeng Biotechnol. 2015;3:1-12.

19. Meng D, Francis L, Thompson ID, Mierke C, Huebner H, Amtmann A, et al. Tetracycline-encapsulated P(3HB) microsphere-coated 45S5 Bioglass( $(\AA)$-based scaffolds for bone tissue engineering. J Mater Sci Mater Med. 2013;24(12):2809-17.

20. Hutchens SA, Hing KA. Efficacy of silicate-substituted calcium phosphate with enhanced strut porosity as a 
standalone bone graft substitute and autograft extender in an ovine distal femoral critical defect model. J Mater Sci Mater Med. 2016;27(1):1-12.

21.Parfitt AM. Bone histomorphometry: Standardization of nomenclature, symbols and units (summary of proposed system). Bone. 1988;9(1):67-9.

22. Magri AMP, Fernandes KR, Assis L, Mendes NA, da Silva Santos ALY, de Oliveira Dantas E, et al. Photobiomodulation and bone healing in diabetic rats: evaluation of bone response using a tibial defect experimental model. Lasers Med Sci. 2015;30(7):1949-57.

23. Fernandes KR, Magri AMP, Kido HW, Parisi JR, Assis L, Fernandes KPS, et al. Biosilicate/PLGA osteogenic effects modulated by laser therapy: In vitro and in vivo studies. J Photochem Photobiol B Biol. 2017;173(June):258-65.

24.Tim CR, Pinto KNZ, Rossi BRO, Fernandes K, Matsumoto MA, Parizotto NA, et al. Low-level laser therapy enhances the expression of osteogenic factors during bone repair in rats. Lasers Med Sci. 2014;29(1):147-56.

25.Lirani-Galvão AP, Jorgetti V, da Silva OL. Comparative study of how low-level laser therapy and low-intensity pulsed ultrasound affect bone repair in rats. Photomed Laser Surg. 2006;24(6):735-40.

26. Wang X, Schröder HC, Wiens M, Ushijima H, Müller WEG. Bio-silica and bio-polyphosphate: Applications in biomedicine (bone formation). Curr Opin Biotechnol. 2012;23(4):570-8.

27.Müller WEG, Tolba E, Schröder HC, Diehl-Seifert B, Link T, Wang X. Biosilica-loaded poly( $\varepsilon$-caprolactone) nanofibers mats provide a morphogenetically active surface scaffold for the growth and mineralization of the osteoclast-related SaOS-2 cells. Biotechnol J. 2014;9(10):1312-21.

28.Wang X, Schröder HC, Grebenjuk V, Diehl-Seifert B, Mailänder V, Steffen R, et al. The marine sponge-derived inorganic polymers, biosilica and polyphosphate, as morphogenetically active matrices/scaffolds for the differentiation of human multipotent stromal cells: Potential application in 3D printing and distraction osteogenesis. Mar Drugs. 2014;12(2):1131-47.

29.Gabbai-Armelin PR, Kido HW, Cruz MA, Prado JPS, Avanzi IR, Custódio MR, et al. Characterization and Cytotoxicity Evaluation of a Marine Sponge Biosilica. 2018;25(1):65-75.

30.Jones DS, Flood BE, Bailey J V. Metatranscriptomic insights into polyphosphate metabolism in marine sediments. ISME J. 2016;10(4):1015-9.

31.Churchman SM, Boxall SA, McGonagle D, Jones EA. Predicting the Remaining Lifespan and Cultivation-Related Loss of Osteogenic Capacity of Bone Marrow Multipotential Stromal Cells Applicable across a Broad Donor Age Range. Stem Cells Int. 2017;2017:1-10.

32.Fernandes JS, Gentile P, Pires RA, Reis RL, Hatton P V. Multifunctional bioactive glass and glass-ceramic biomaterials with antibacterial properties for repair and regeneration of bone tissue. Acta Biomater. 2017;59:2-11.

33. Wiens M, Wang X, Schröder HC, Kolb U, Schloßmacher U, Ushijima H, et al. The role of biosilica in the osteoprotegerin/RANKL ratio in human osteoblast-like cells. Biomaterials. 2010;31(30):7716-25.

34.van de Watering FCJ, van den Beucken JJJP, Walboomers XF, Jansen JA. Calcium phosphate/poly(d,I-lactic-coglycolic acid) composite bone substitute materials: Evaluation of temporal degradation and bone ingrowth in a rat critical-sized cranial defect. Clin Oral Implants Res. 2012;23(2):151-9.

35.Qi X, Ye J, Wang Y. Improved injectability and in vitro degradation of a calcium phosphate cement containing poly(lactide-co-glycolide) microspheres. Acta Biomater. 2008;4(6):1837-45.

36. Bonewald LF, Mundy GR. Role of transforming growth factor beta in bone remodeling: A review. Connective Tissue Research. 1989.

37.Chen G, Deng C, Li YP. TGF- $\beta$ and BMP signaling in osteoblast differentiation and bone formation. Int J Biol Sci. 2012;8(2):272-88.

38. Yang YQ, Tan YY, Wong R, Wenden A, Zhang LK, Rabie ABM. The role of vascular endothelial growth factor in ossification. Int J Oral Sci. 2012;4(2):64-8.

39. Hoppe A, Güldal NS, Boccaccini AR. A review of the biological response to ionic dissolution products from bioactive 
glasses and glass-ceramics. Biomaterials. 2011;32(11):2757-74.

40. Rahaman MN, Day DE, Sonny Bal B, Fu Q, Jung SB, Bonewald LF, et al. Bioactive glass in tissue engineering. Acta Biomater. 2011;237(6):73-82.

41.Granito RN, Rennõ AC, Ravagnani C, Bossini PS, Mochiuti D, Jorgetti V, et al. In vivo biological performance of a novel highly bioactive glass-ceramic (Biosilicate $\AA$ ): A biomechanical and histomorphometric study in rat tibial defects. J Biomed Mater Res - Part B Appl Biomater. 2011;97 B(1):139-47.

42. Oliveira AL, Costa SA, Sousa RA, Reis RL. Nucleation and growth of biomimetic apatite layers on 3D plotted biodegradable polymeric scaffolds: Effect of static and dynamic coating conditions. Acta Biomater. 2009;5(5):162638.

43. Granito RN, Ribeiro DA, Rennó ACM, Ravagnani C, Bossini PS, Peitl-Filho O, et al. Effects of biosilicate and bioglass 45S5 on tibial bone consolidation on rats: a biomechanical and a histological study. J Mater Sci Mater Med. 2009 Dec;20(12):2521-6.

44. Wheeler TS, Sbravati ND, Janorkar A V. Mechanical \& cell culture properties of elastin-like polypeptide, collagen, bioglass, and carbon nanosphere composites. Ann Biomed Eng. 2013;41(10):2042-55.

(c) (1) 2020 by the authors. Submitted for possible open access publication under the terms and
conditions of the Creative Commons Attribution (CC BY NC) license (https://creativecommons.org/licenses/by-nc/4.0/). 